Article

\title{
Fuzzy Logic Control of a Battery Energy Storage System for Stability Improvement in an Islanded Microgrid
}

\author{
Naowarat Tephiruk ${ }^{1, *, \dagger}$, Weerawoot Kanokbannakorn ${ }^{1}$, Thongchart Kerdphol ${ }^{2}$ (D), \\ Yasunori Mitani ${ }^{2}$ and Komsan Hongesombut ${ }^{1,+}$ (iD \\ 1 Department of Electrical Engineering, Faculty of Engineering, Kasetsart University, \\ Bangkok 10900, Thailand; fengwwk@ku.ac.th (W.K.); fengksh@ku.ac.th (K.H.) \\ 2 Department of Electrical and Electronic Engineering, Kyushu Institute of Technology, Kitakyushu, \\ Fukuoka 804-8550, Japan; thongchartkerd@gmail.com (T.K.); mitani@ele.kyutech.ac.jp (Y.M.) \\ * Correspondence: naowarat.t@ku.th; Tel.: +66-2-797-0999-1577 \\ + These authors contributed equally to this work.
}

Received: 14 April 2018; Accepted: 16 May 2018; Published: 19 May 2018

\begin{abstract}
In this study, the active and reactive power control of a battery energy storage system (BESS) using fuzzy logic control to maintain the voltage and frequency stability of the islanded Mae Sariang microgrid is presented. The main scope of the presented study is to cogitate the effectiveness of the BESS controller in view of fluctuations of frequency/voltage subjected to a disturbance occurring in the islanded microgrid. In the Mae Sariang microgrid system, the electricity is produced from two renewable energy resources (RESs), i.e., hydro and solar PV. The use of these clean energy sources has become a main problem, envisaging the output power uncertainties from RESs. Further, such power uncertainty raises power quality problems and leads to power failure. To overcome such problems, the proposed fuzzy logic control (FLC) approach is applied for the BESS controller to improve the stability of the islanded Mae Sariang microgrid. The proposed FLC is intended to provide the BESS with well-established attributes of dynamical response to disturbance, which is analyzed by a predictive model. The proposed FLC has been investigated and compared with the robust control method, which is analyzed by a mathematical model using the system identification technique. The modeling of the microgrid system with BESS is implemented and verified on the DIgSILENT PowerFactory software. The simulation result illustrates that both of the control approaches allow the dynamic stability of the microgrid and the maintenance of frequency and voltage within acceptable ranges. However, the proposed BESS fuzzy logic control is less prone to uncertainty than the BESS robust control. Furthermore, in the proposed BESS fuzzy logic control, the microgrid frequency and voltage rapidly return to their normal steady-state condition and the size of the BESS is smaller than the BESS robust control.
\end{abstract}

Keywords: frequency stability; voltage stability; battery energy storage system; microgrid; fuzzy logic control; robust control

\section{Introduction}

For several decades, the utilization of renewable energy resources (RESs), such as wind, solar, and biomass energy, instead of fossil fuel resources has received more attention worldwide due to the increasing awareness regarding issues concerning global warming. However, RESs have significantly created discontinuity in power transfer, which affects the security, reliability, and power quality of power systems. Thus, the concept of the microgrid is considered as a possible solution to deal 
with such problems. The microgrid is composed of several small-power sources and energy storage systems (ESSs), which are well known as distributed energy resources (DERs) to supply power to the local-load areas. DERs are connected to the AC bus of the microgrid through power electronic devices, such as inverters. The microgrid can operate by connecting to a main grid, which is known as the grid-connected mode, or operate independently when a fault occurs in the main grid, which is known as the islanded mode [1-4].

In a grid-connected mode, the power is usually stored on the rotating masses of the synchronous generators in the main grid. When disturbances occur in the main grid, the microgrid can quickly respond to changes. As a result, the microgrid is able to maintain the frequency/voltage stability. Thus, in this mode the power within the microgrid is balanced by the main grid. In an islanded mode, the DERs are primarily responsible for maintaining the frequency/voltage stability within the microgrid. However, the behavior of the microgrid in this mode shows low inertia characteristics, because many devices are connected to the microgrid via the inverters. As a result, the DERs that have a slow response to disturbances may cause power imbalance and lead to frequency/voltage instability in the microgrid. This phenomenon is a challenge for energy management in the microgrid. To solve this problem, many researchers have shown interest in studying the installation of ESS in the microgrid to provide the voltage and frequency stability and to maintain the balance of the active and reactive powers. However, the applied ESS should have a fast response to the disturbances occurring in the islanded microgrid. Hence, the fast charge/discharge rate control method of the ESS has been significant and needs to be considered [5-9].

Several control methods have been applied for the ESS controller. Each control method requires mathematical models for analysis to design the ESS controllers, such as a proportional-integral (PI) control or robust control. The PI control is the most applied method because it is simple to use and provides satisfactory performance. However, the performance of the PI control is degraded when the operating condition of the system changes [10]. Therefore, the robust method has been an option to solve this issue. It actively permutes the operating conditions of the system and enables a fast response to the disturbances that occur. As a result, the ESS controller can quickly respond to deliver the active and reactive powers and reduce the frequency and voltage fluctuations of the system. However, this approach is popular to use for a single-input, single-output (SISO) system since an SISO system can be easy analyzed by a mathematical model $[11,12]$. Because of such restrictions, the fuzzy logic control method is another option that is applied to the design of ESS controllers. This method analyzes the system from the knowledge and experience of the expert. It does not need to linearize the system to be a mathematical model. Thus, this method is suitable for the complex, uncertain, SISO and multi-input, multi-output (MIMO) systems [13].

Nowadays, the electrical system in the area of Mae Sariang District, Mae Hong Son Province, Thailand has supplied electricity from the Hod's substation, which is about $110 \mathrm{~km}$ away. This system is a $22 \mathrm{kV}$ distribution system of the Provincial Electricity Authority of Thailand (PEA), and it is called the Mae Sariang microgrid system. Even in this area, the electricity is produced from various types of small power sources such as diesel power plants, micro-hydro power plants, and solar power plants, but these are very uncertain for electricity production and insufficient for local load demand. Further, such uncertainty results power quality problems and leads to power failure. In the worst case, if a fault occurs at the main transmission line from the Hod's substation, the Mae Sariang microgrid will blackout immediately. Therefore, the installation of ESS to maintain stability in the Mae Sariang microgrid is necessary.

The ESS technologies are divided into mechanical (such as pumped hydro, compressed air, and flywheels), electromagnetic (such as superconducting magnetic energy storage), electrochemical (such as hydrogen, flow batteries, and batteries) and thermal types. Operation principles and characteristics of each type have been demonstrated and compared in terms of power rating, response time, lifetime, discharge time, efficiency, and operation costs [14]. Recently, battery energy storage systems (BESSs) have become one of the most popular ESS technologies. The BESS has several 
categories, including lithium-ion, lead-acid, nickel-cadmium, sodium sulfur, and vanadium redox flow batteries [15]. It is known that the lithium-ion battery is characterized by a high discharge rate, high specific power and energy, as well as investment and operation cost reductions. Thus, this study uses a lithium-ion battery to cope with the output power uncertainties and dynamic problems from RESs in the Mae Sariang's microgrid system.

A pilot project of Mae Sariang's microgrid system consists of a diesel power plant, a micro-hydro power plant, and a solar power plant without a BESS installed. Thus, this study focuses on the stabilization problems in the Mae Sariang's microgrid system. Recently, several designed concepts of BESS have been tested on a Real Time Digital Simulator (RTDS). For example, in [16], the conceptual of microgrid system (as in Figure 1.) was tested on an RTDS to study a critical clearing time of overcurrent protection.

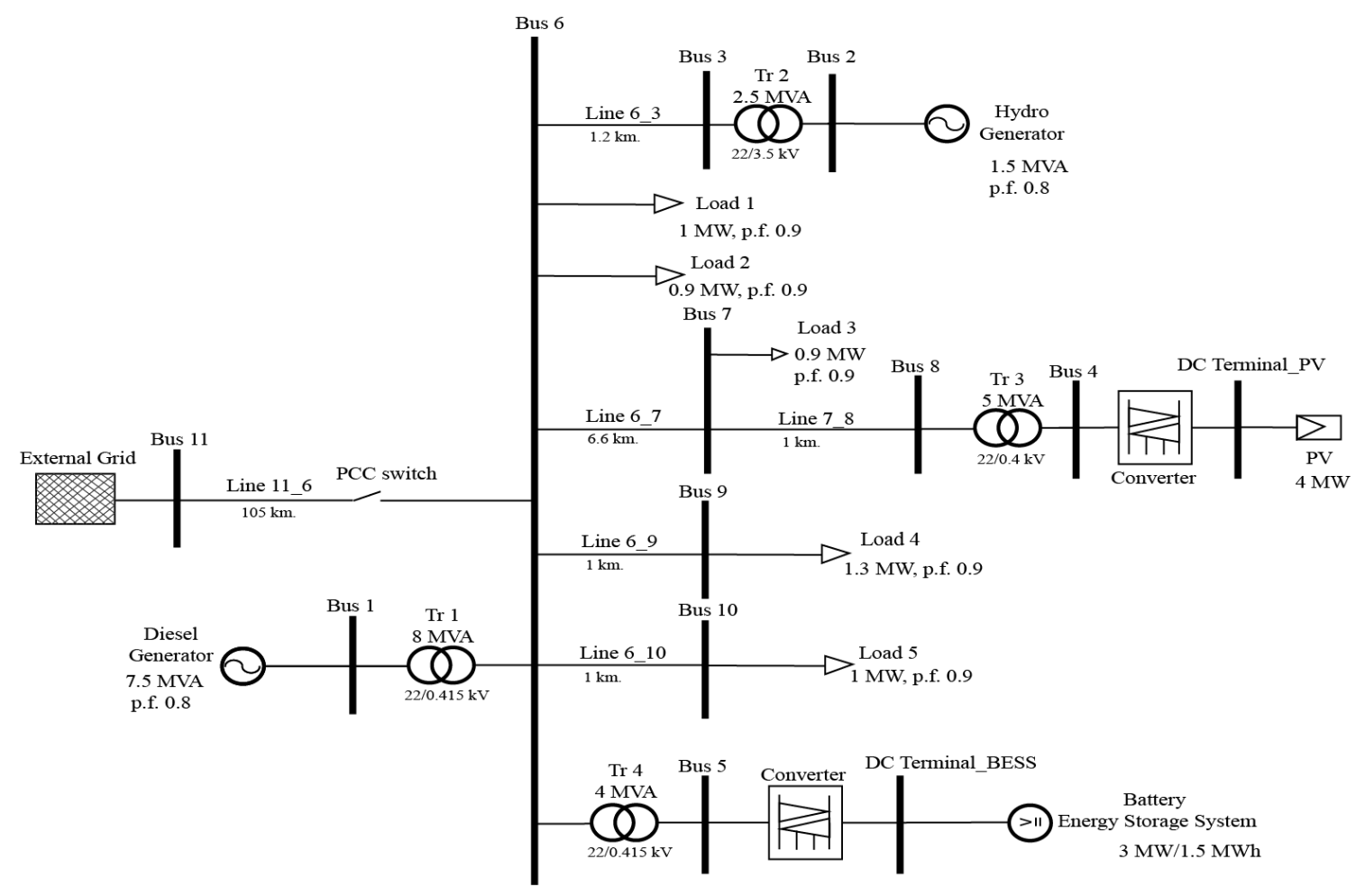

Figure 1. Configuration of the proposed microgrid system.

This study is inspired by the features of the ESS discussed earlier with a focus on improving the frequency/voltage stability in the Mae Sariang's microgrid system in the case of an islanding condition. The fuzzy logic control and robust control methods are applied for the active and reactive power controls of the BESS in the microgrid during contingencies, to stabilize the frequency and voltage dynamic responses. The simulation results are implemented on the DIgSILENT PowerFactory software.

\section{The Perspective of Microgrid}

The microgrid is a single, manageable, self-sufficient power system, which consists of distributed generation (DG), ESSs, control devices, and loads, in which the DG and ESS are directly linked with the demand side. The microgrid can execute either in a grid-connected mode or in an islanded mode [17-19]. A pilot project of the Mae Sariang microgrid system model, which was created and funded by the United Nations Development Program (UNDP), is reported in [20-23]. The Mae Sariang microgrid model consists of three parts: the generation part, the storage part, and the load part. The configuration details of the studied system are demonstrated in Figure 1 (see parameter details of the studied system in Appendix A). 


\section{Operation Modes}

Figure 2 exhibits the permutation diagram of the microgrid operations. In a grid-connected mode, the microgrid is connected to exchange the active and reactive powers with a main grid via the switch at the point of common coupling (PCC). When the disturbance occurs in the main grid, the microgrid will transfer from the grid-connected mode to the islanded mode. Therefore, the DG and BESS in the microgrid will automatically supply the power to the local loads. If the alternate operating mode is not successful because of an incidence, the microgrid will become the shutdown mode and lead to the microgrid blackout. Subsequently, the microgrid will resume operation when the main grid returns to the normal state (grid-connected mode) or when the microgrid can properly manage the energy supply to the local load (islanded mode) [24].

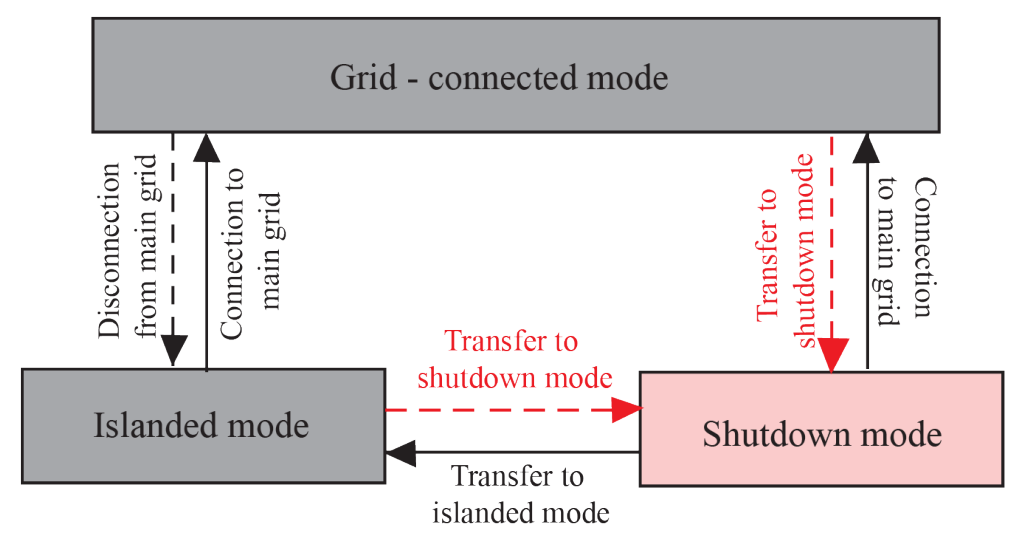

Figure 2. Permutation diagram of the microgrid operation.

In the islanded mode, if the capacity of the DG unit is not sufficient for the local load demand, and the BESS controller cannot respond instantaneously, the microgrid will lose its stability operations and enter the shutdown mode. Hence, this study considers the BESS control methods to prevent the shutdown mode during the transition, stabilizing the frequency and improving the voltage of the microgrid. The BESS control methods are described in detail in Section 3.

\section{The Control Method of BESS}

The BESS control method is the emphatic part of this study, as exhibited in the PQ control block in Figure 3. It is composed of the active power controller of the BESS part (the P controller) and the reactive power controller of the BESS part (the $Q$ controller). The signal of the active power is sent to the loop of the $\mathrm{P}$ controller and the signal of the reactive power is sent to the loop of the Q controller. Further, the output signal is transmitted to the converter and is finally sent back to the microgrid, to minimize the frequency and voltage deviations. When disturbances appear in the microgrid, it may result in the active and reactive power fluctuations and lead to the frequency and voltage deviations. Hence, such fluctuations can be eliminated by the equilibrium control between the power that supplies and the power demand through the BESS control.

Since decades, the fuzzy logic control method has been a widely used scheme, especially in the field of control systems, and it is a highly efficient control method. This method is based on the knowledge and experience of experts, serving as a basis for the intelligent designs, so such method has a human intelligence. Moreover, this method does not require accurate numerical modeling of the system, making it perfect for complex ambiguous, uncertainty, and multi-input systems. The fuzzy logic control method comprises four main parts: fuzzification, control rules, inference system, and defuzzification [25]. In this study, the fuzzy logic control and robust control approaches are applied for the BESS control. The details for each method are demonstrated in Sections 3.1 and 3.2, respectively. 


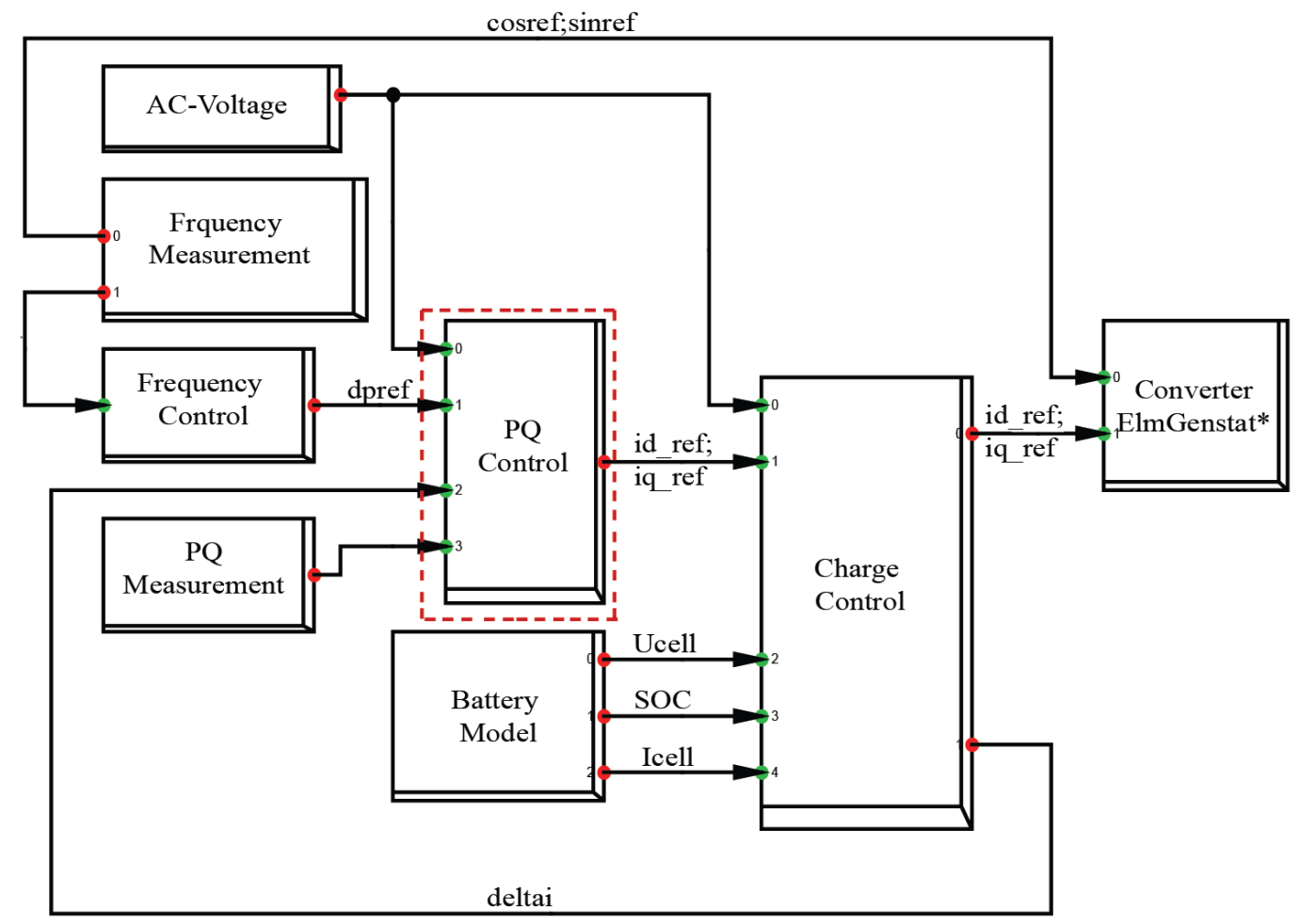

Figure 3. Framework of the BESS controller on DIgSILENT PowerFactory.

\subsection{Establishment of Fuzzy Logic Control}

The fuzzy logic control method is applied with the BESS controller to maintain frequency and voltage stability within the desirable microgrid performance/constraint. The PQ control part inside (see in Figure 3) is the proposed BESS fuzzy logic controller as demonstrated in Figure 4. $\triangle P$ is the error and $\triangle P$ is the BESS active power deviation of the error being the input signal. Idre $f$ is the output signal of the $P$ controller part. These two inputs are divided into five input triangular membership functions; NB (Negative Big), $N$ (Negative), $Z$ (Zero), $P$ (Positive), and PB (Positive Big) as demonstrated in Figure 5. The control rules are indicated as follows: Rule 1: if $\triangle P$ is $N B$ and $\triangle P$ is $P B$, then Idref should be $Z$. These inputs have a total of 25 fuzzy logic control rules, including a convenient way to present a decision rule, which is to employ the decision tables as illustrated in Figure 6a.

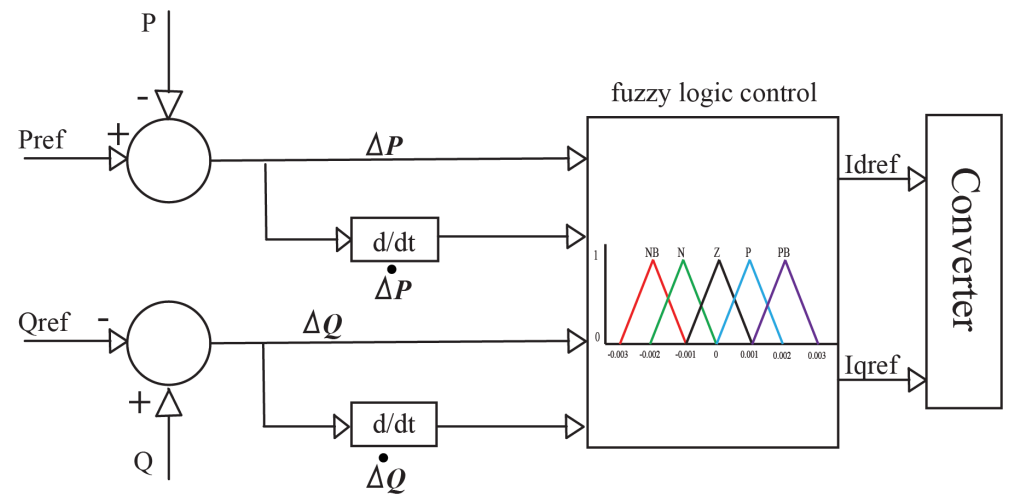

Figure 4. Conformation of the BESS fuzzy logic controller. 

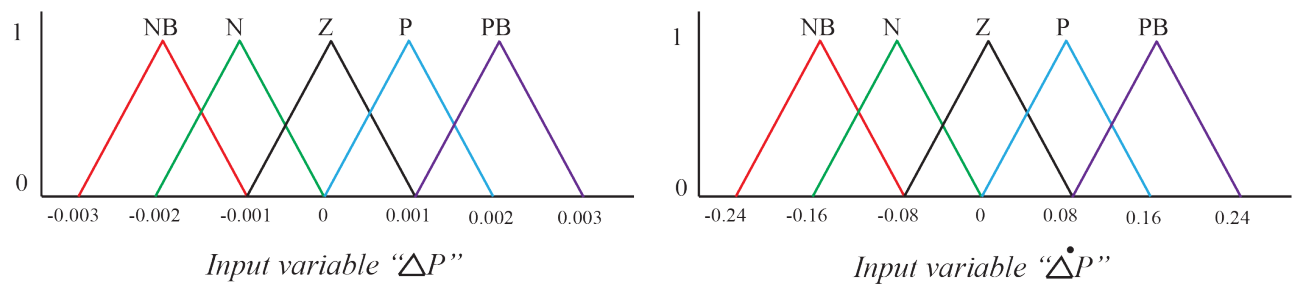

Figure 5. Membership function plots of the P controller.

\begin{tabular}{|c|c|c|c|c|c|}
\hline \multirow{2}{*}{$\triangle \mathbf{P}$} & \multicolumn{5}{|c|}{$\dot{\triangle}$} \\
\cline { 2 - 6 } & $\mathbf{N B}$ & $\mathbf{N}$ & $\mathbf{Z}$ & $\mathbf{P}$ & $\mathbf{P B}$ \\
\hline $\mathbf{N B}$ & $N B$ & $N$ & $N$ & $N$ & $Z$ \\
\hline $\mathbf{N}$ & $N$ & $N$ & $Z$ & $Z$ & $P$ \\
\hline $\mathbf{Z}$ & $N$ & $N$ & $Z$ & $P$ & $P$ \\
\hline $\mathbf{P}$ & $N$ & $Z$ & $P$ & $P$ & $P$ \\
\hline $\mathbf{P B}$ & $Z$ & $P$ & $P$ & $P$ & $P B$ \\
\hline
\end{tabular}

(a)

\begin{tabular}{|c|c|c|c|c|c|}
\hline \multirow{2}{*}{$\Delta \mathbf{Q}$} & \multicolumn{5}{|c|}{$\dot{\Delta}$} \\
\cline { 2 - 6 } & $\mathbf{N B}$ & $\mathbf{N}$ & $\mathbf{Z}$ & $\mathbf{P}$ & $\mathbf{P B}$ \\
\hline $\mathbf{N B}$ & $N B$ & $N$ & $N$ & $N$ & $Z$ \\
\hline $\mathbf{N}$ & $N$ & $N$ & $Z$ & $Z$ & $P$ \\
\hline $\mathbf{Z}$ & $N$ & $N$ & $Z$ & $P$ & $P$ \\
\hline $\mathbf{P}$ & $N$ & $Z$ & $P$ & $P$ & $P$ \\
\hline $\mathbf{P B}$ & $Z$ & $P$ & $P$ & $P$ & $P B$ \\
\hline
\end{tabular}

(b)

Figure 6. Fuzzy rule base table. (a) The P controller and (b) the Q controller.

Similarly, $\triangle Q$ is the error and $\triangle Q$ is the change of the error of the BESS reactive power chosen to be the input signal. Iqref is selected as the output signal of the $\mathrm{Q}$ controller part. The proposed method for determining of the membership functions and fuzzy logic control rules of the $Q$ controller part is the same as the $\mathrm{P}$ controller part. The fuzzy rule base table and the membership function plots of the $\mathrm{Q}$ controller are illustrated in Figures $6 \mathrm{~b}$ and 7, respectively.
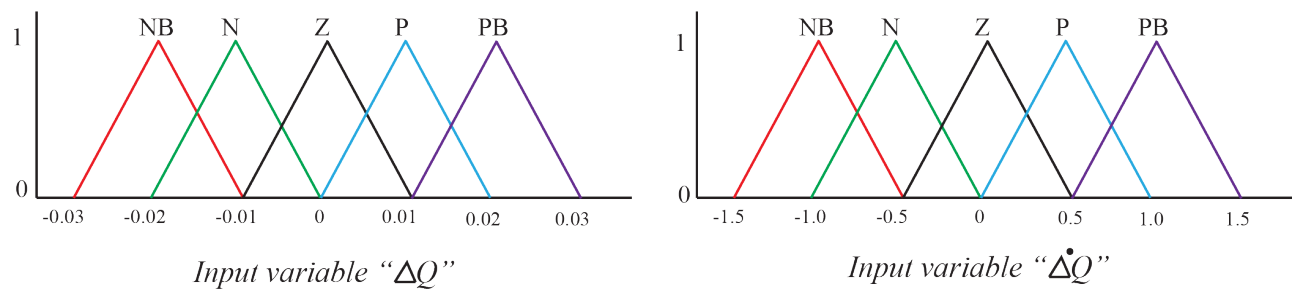

Figure 7. Membership function plots of the $Q$ controller.

\subsection{Establishment of Robust Control}

To examine the efficicency of the BESS fuzzy logic control method, the BESS robust control method is also designed for the frequency/voltage stabilization and improving the dynamic response in the islanded microgrid. In this study, the $\mathrm{Q}$ controller is primarily designed to maintain a steady voltage of the microgrid system and a perspective of the studied microgrid system analysis process is shown in Figure 8. The process is expressed by the following steps.

Step 1: Formulate the microgrid model employed in this study using the DIgSILENT PowerFactory software, as demonstrated in Figure 1.

Step 2: Create a mathematical model of the studied microgrid using the system identification technique, to design a robust BESS controller for the $\mathrm{Q}$ controller loop.

First, the input and output signals of the microgrid system are assigned. In this study, the q-axis component of the current fed into the converter (Iqref) and the BESS reactive power deviation $(\triangle Q)$ are the output and input signals of the $Q$ controller loop design. The swept-frequency signal is injected at the input point. This process is accomplished by the DIgSILENT PowerFactory software. Second, the input and output signals are exported to the MATLAB software to obtain the appropriate transfer 
function of the microgrid system using the system identification technique. Further, the state-space equations of the microgrid system are established according to Equation (1):

$$
\begin{gathered}
x_{t+1}=A x_{t}+B u_{t}+G v_{t} \\
y_{t}=C x_{t}+D u_{t}+v_{t}
\end{gathered}
$$

where $x_{t} \in R^{n}, y_{t} \in R^{l}, u_{t} \in R^{m}$, and $v_{t} \in R^{n}$ are the input, output, and disturbance states, respectively, by assigning $A \in R^{n \times n}, B \in R^{n \times m}, C \in R^{l \times n}, D \in R^{l \times m}$, and $G \in R^{n \times l}$, which are the state estimation matrices.

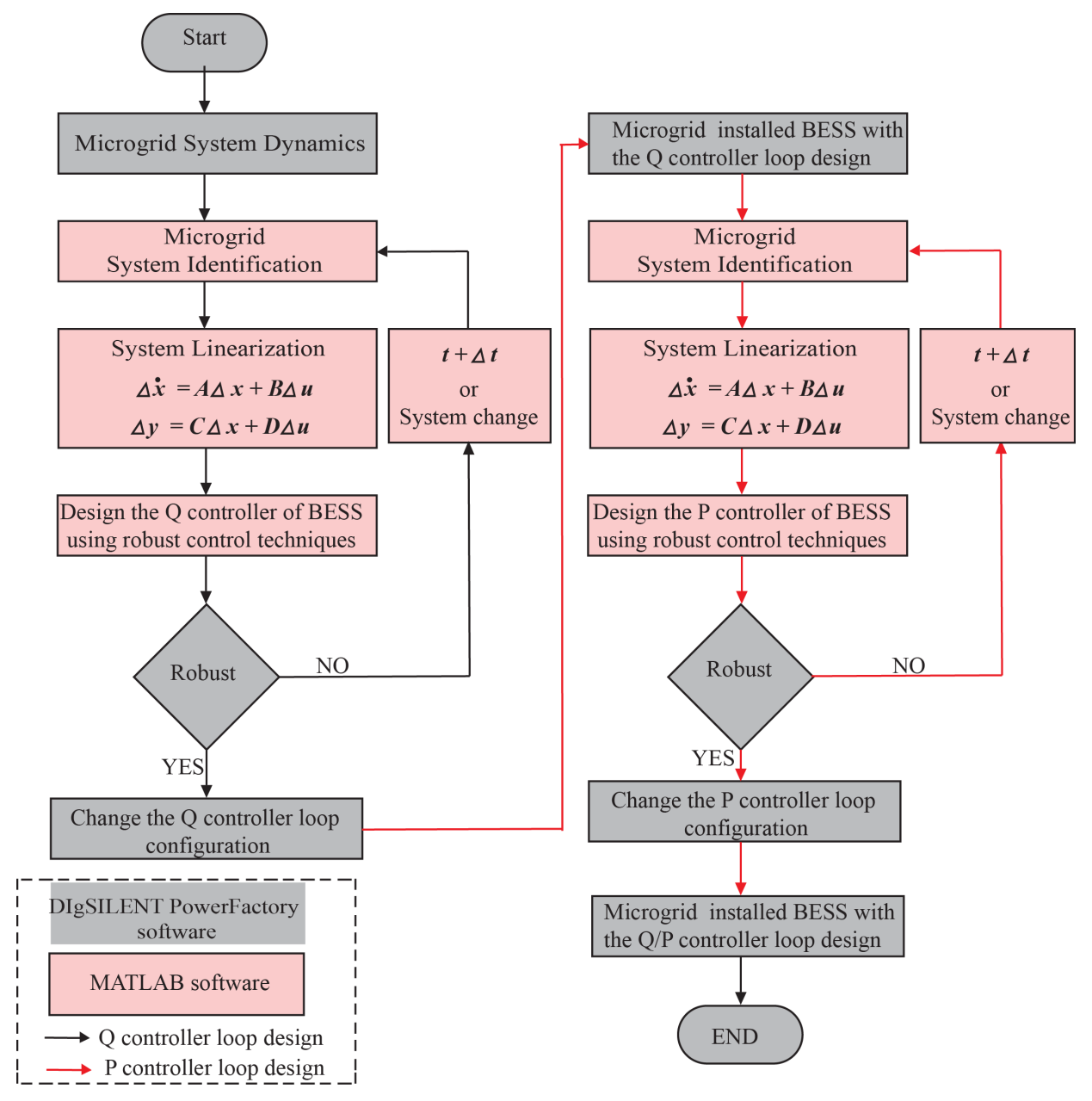

Figure 8. Perspective of the studied microgrid system analysis process.

Subsequently, the system linearization utilizing the gradient search is estimated to determine the applicable transfer function of the microgrid system, as expressed as

$$
\min _{\theta}\|e(\theta)\|_{2} \approx \min _{\theta}^{\min }\left\|e\left(\theta_{k}\right)+J\left(\theta_{k}\right)\left(\theta-\theta_{k}\right)\right\|_{2}
$$

Step 3: Formulate the robust BESS controller.

$G_{0 q}(s)$ from the previous step is administered for the robust BESS controller utilizing the robust control strategy. It has the following processes: First, choose the weighting transfer functions $(\omega(s))$, which are selected based on low frequency response to offer the gain of the small sensitivity function at such frequency range. Second, $\omega(s)$ is applied for determining the plant transfer function $\left(G_{s q}\right)$, as written in Equation (3). 


$$
G_{s q}=\omega_{2 q} G_{0 q} \omega_{1 q}
$$

where $\omega_{1 q}$ is a lead compensator, and $\omega_{2 q}$ is a lag compensator of the $Q$ controller loop.

Third, establish the transfer function of the perturbed plant $\left(G_{\triangle}\right)$ to formulate the extent of the robust stability via $\frac{1}{\gamma}$ factor according to Equation (4). Figure 9 demonstrates the robust stability problem.

$$
G_{\triangle q}=\left\{\left(M_{s q}+\Delta M_{s q}\right)^{-1}\left(N_{s q}+\Delta N_{s q}\right)\left\|\left[\begin{array}{cc}
\Delta N_{s q} & \triangle M_{s q}
\end{array}\right]\right\|_{\infty} \leq \frac{1}{\gamma}\right\}
$$

where $M_{s q}, N_{s q}, \triangle M_{s q}$, and $\triangle N_{s q}$ are the transfer functions of the uncertainties of the plant $G_{0 q}$ and assigning $G_{s q}=M_{s q}^{-1} \triangle N_{s q}$.

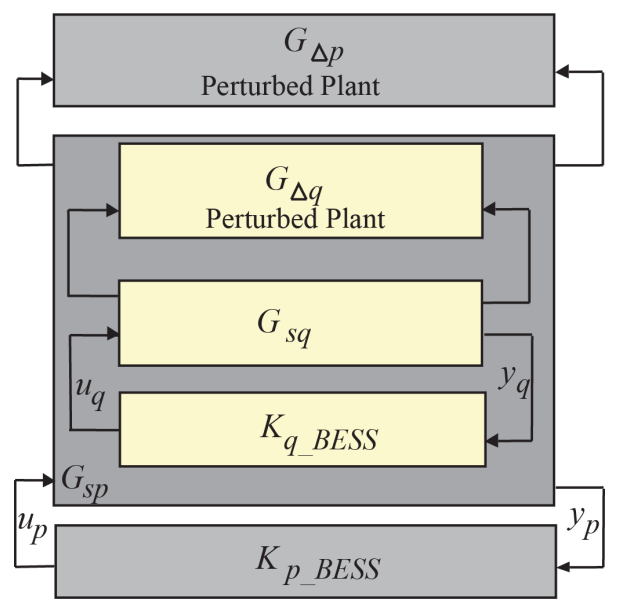

Figure 9. Robust stability problem.

Subsequently, create the BESS controller $\left(K_{q_{-} B E S S}\right)$ of the Q controller loop as shown in the yellow part of Figure 9, and $K_{q_{-} B E S S}$ can be computed by Equation (5). The first loop is defined to $\gamma>\gamma_{\text {min }}$. Further, the value of $\gamma$ is reduced until $\gamma \approx \gamma_{\min }$, and this value is the most appropriate for the robust controller.

$$
\left\|\left[\begin{array}{c}
I \\
K_{q_{-} B E S S}
\end{array}\right]\left(I-G_{s q} K_{q_{-} B E S S}\right)\left[\begin{array}{ll}
I & G_{s q}
\end{array}\right]\right\| \leq \gamma .
$$

However, since the study of the microgrid system is complicated, the designed controller usually has a high order, and the controller is implemented as a second-order arrangement. Thereby, this study needs to reduce the order of controller using the suitable reduction strategy in the robust control toolbox of MATLAB [26]. Finally, for the $Q$ controller loop design, $K_{q_{-} B E S S}$ is supplanted in constituent of the $\mathrm{Q}$ controller loop part. This process is accomplished utilizing the DIgSILENT PowerFactory software.

Finally, the reasonable transfer function for the $Q$ controller loop can be represented in Equation (6):

$$
G_{0 q}(s)=\frac{U_{q}}{Y_{q}}
$$

Step 4: Design the robust BESS controller $\left(K_{p_{-} B E S S}\right)$ for the P controller loop.

$K_{p_{-} B E S S}$ has similar design processes with the Q controller loop. However, the microgrid system includes the robust $\mathrm{Q}$ controller loop of the BESS, which is applied for the P controller loop design. The $\mathrm{d}$-axis component of the current is fed into the converter (Idref) and the BESS real power deviation $(\triangle P)$ is the output/input signal of the $\mathrm{P}$ controller loop design. The robust stability problem structure 
is shown in the gray shaded blocks of Figure 9. The BESS robust controller for the Q and P controller loops can be represented in Equations (7)-(8), respectively. The state-space matrices $(A, B, C$, and $D)$ and the weighting transfer functions $(\omega(s))$ are shown in Appendix B.

$$
\begin{gathered}
K_{q_{-} B E S S}(s)=\left[\frac{10 s+1}{3.333 s+1}\right]\left[\frac{1}{2.045 s+1}\right] \\
K_{p_{-} B E S S}(s)=\left[\frac{10.10 s+1}{3.333 s+1}\right]\left[\frac{3.048 s+1}{0.07 s+1}\right] .
\end{gathered}
$$

Eventually, the achievement appraisal of the proposed robust BESS control is accomplished in Section 4.

\section{Simulation Results}

The microgrid is illustrated in Figure 1. It is used to investigate the control algorithms of the active and reactive power injections of the BESS, to maintain frequency and voltage stability in the microgrid. In this study, the maximum allowable frequency and voltage change is simulated to $5 \%$ for its nominal value. The simulation was executed for $30 \mathrm{~s}$ in the DIgSILENT PowerFactory software.

To examine the performance of the proposed BESS controller in this study, two different scenarios were simulated, and each scenario was divided into three comparison cases as follows: Case I: the microgrid without a BESS, Case II: the microgrid with a BESS fuzzy logic controller, and Case III: the microgrid with a BESS robust controller.

Scenario I: The microgrid operates in the islanded mode and has a very low inertia behavior. The simulation is executed for $30 \mathrm{~s}$. The PCC switch is opened after $5 \mathrm{~s}$, which indicates the isolation of the microgrid. The microgrid is then operated in the islanded mode for $15 \mathrm{~s}$, and the hydro generator is then disconnected from the microgrid. This is an occurrence of the severe input disturbance. The frequency and voltage responses of the microgrid at Bus 6 and the management of the power generation in Scenario I demonstrated in Figures 10 and 11, respectively. When the microgrid operates in the islanded mode, the frequency and voltage is rapidly changed due to the variations of the power unbalance between the supply and demand in the microgrid. In Case I, as demonstrated in the red line, it cannot maintain the microgrid stability. However, in Cases II and III, it can maintain the frequency and voltage within the acceptable range as demonstrated in black and blue lines, respectively. The amplified windows of Figures 10 and 11 clearly show that the rate of change of frequency $(\mathrm{df} / \mathrm{dt})$ of Case I is equal to $-0.488 \mathrm{~Hz} / \mathrm{s}$, while the $\mathrm{df} / \mathrm{dt}$ of Case II and Case III are equal to $-0.076 \mathrm{~Hz} / \mathrm{s}$ and $-0.185 \mathrm{~Hz} / \mathrm{s}$, respectively. Likewise, the rate of change of voltage $(\mathrm{dV} / \mathrm{dt})$ of Cases I, II, and III are equal to -8 p.u./s (or $176 \mathrm{~V} / \mathrm{ms}$ ), -0.6 p.u./s (or $13.2 \mathrm{~V} / \mathrm{ms}$ ), and -1 p.u. / s (or $22 \mathrm{~V} / \mathrm{ms}$ ), respectively.

At $15 \mathrm{~s}$, the hydro generator is disconnected from the microgrid, resulting in frequency and voltage fluctuations. This issue can be solved by utilizing the BESS in Cases II and III. However, in the case of the microgrid with a BESS fuzzy logic controller installed (Case II) outperforms Case III (the microgrid with a BESS robust controller installed). In Case II, when disturbance occurs, the frequency becomes the lowest at $49.974 \mathrm{~Hz}$, and the lowest voltage is 1.003 p.u. The frequency is rapidly restored to a constant value within $1 \mathrm{~s}$, which is considered a highlight in this case.

Scenario II: The microgrid operates in the islanded mode and has a high inertia behavior, with an increase in the load and uncertainty of the PV.

The simulation is executed for $30 \mathrm{~s}$. The microgrid initially operates in the islanded mode at $5 \mathrm{~s}$. At $15 \mathrm{~s}$, Load 1 is increased by $50 \%$ from its nominal value, and the PV is then deactivated at $15-18 \mathrm{~s}$. 


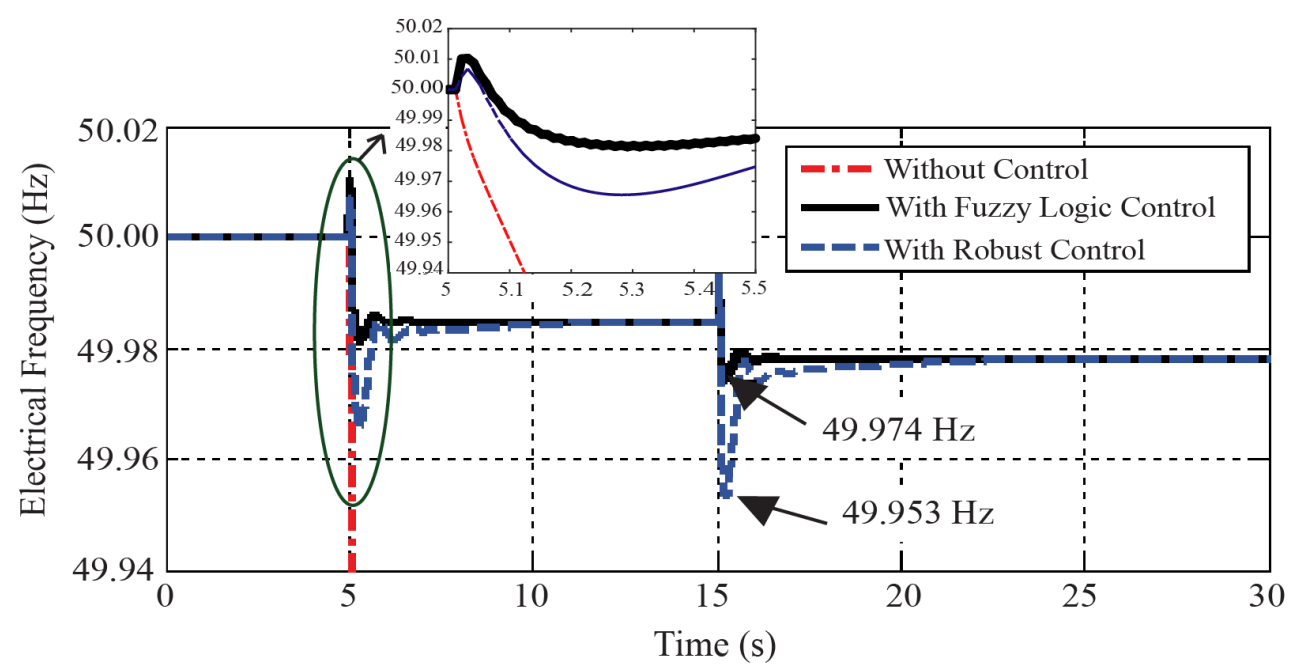

Figure 10. Frequency response of the microgrid at Bus 6 in Scenario I.

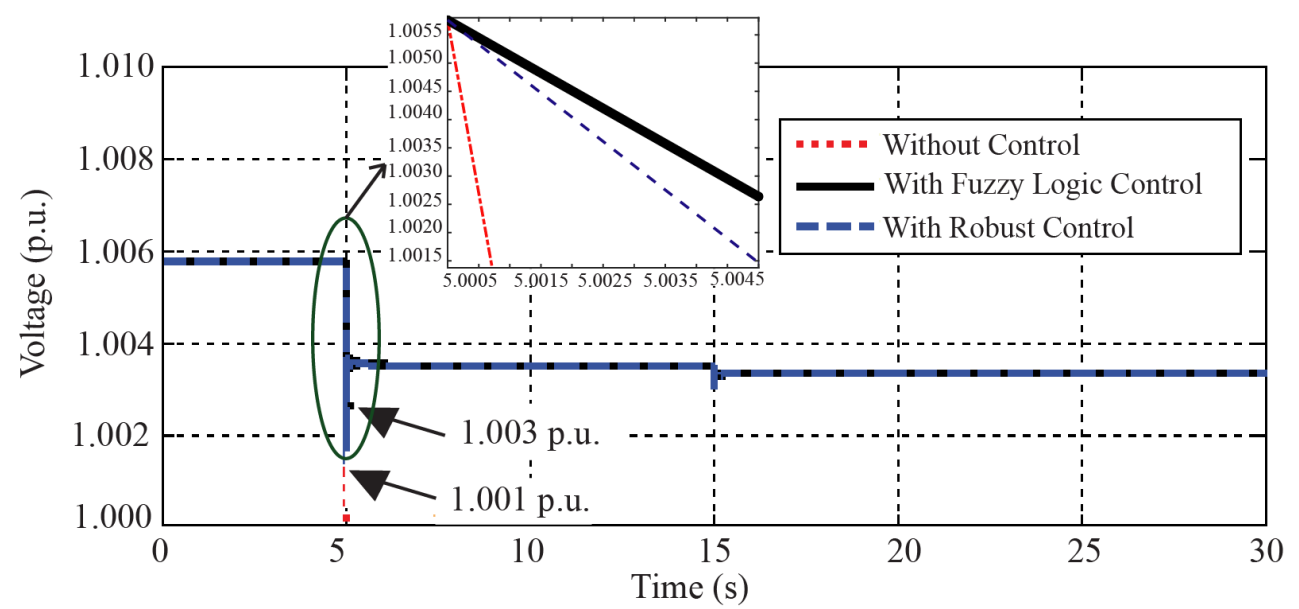

Figure 11. Voltage response of the microgrid at Bus 6 in Scenario I.

Figures 12 and 13 indicate the frequency and voltage responses at Bus 6 in Scenario II, respectively. The blue line represents the frequency and voltage at Bus 6 of the BESS robust controller case and the black line is the frequency and voltage at Bus 6 of the BESS fuzzy logic controller case. It can be observed that, after the disturbance, the blue line has a minimum frequency of $49.966 \mathrm{~Hz}$ and has a minimum voltage of 1.000 p.u., while the frequency and voltage changes in a black line is small. In other words, the case where a BESS fuzzy logic controller is installed is superior in terms of frequency and voltage responses, with excellent resistance to disturbances. Hence, this case can effectively maintain the balance between the power supply and power demand in the island mode of the microgrid. These can be confirmed in the amplified windows of Figures 12 and 13, showing that the BESS fuzzy logic controller has a better response. 


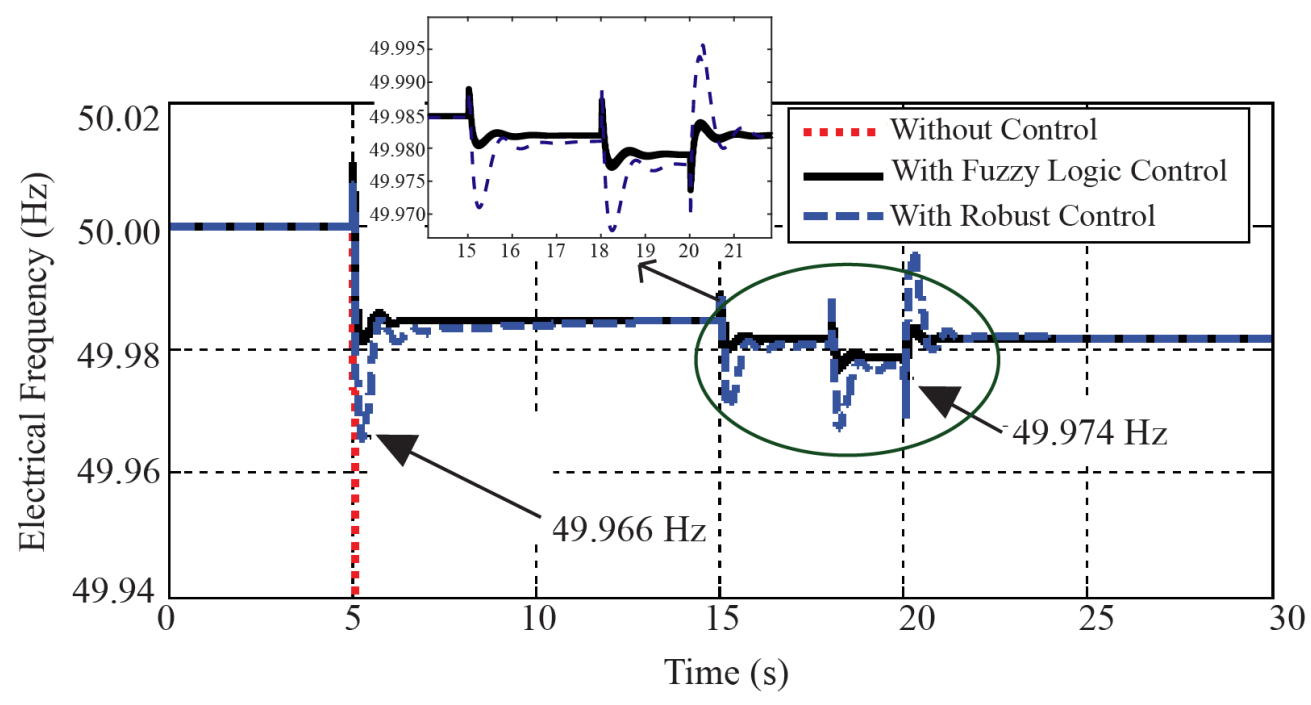

Figure 12. Frequency response of the microgrid at Bus 6 in Scenario II.

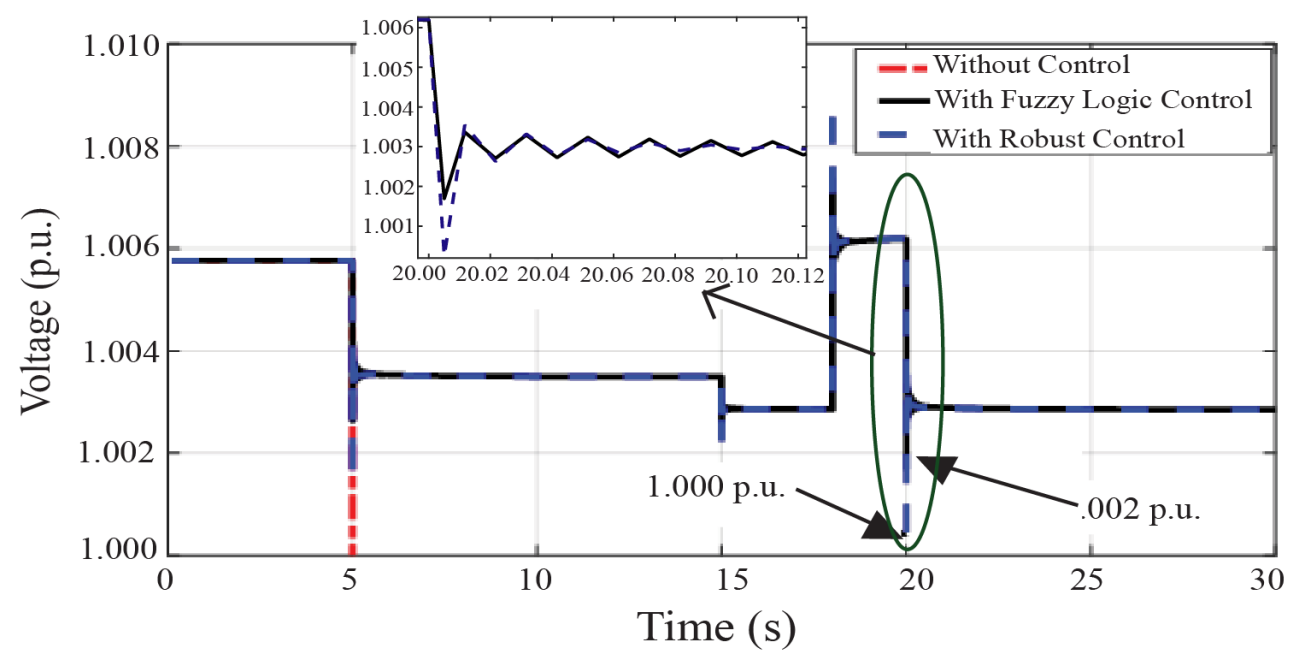

Figure 13. Voltage response of the microgrid at Bus 6 in Scenario II.

Figure 14 illustrates comparison results of the BESS sizing used to improve the dynamic stability of the microgrid. The rated capacity of BESS is equal to $3 \mathrm{MW}$ (1.5 MWh). The state of charge (SOC) is kept between 20 and $80 \%$ of the rated capacity (0.3 MWh to $1.2 \mathrm{MWh}$ ) for both absorption and injection. In Scenario I, the BESS capacity with a fuzzy logic controller is equal to $0.589 \mathrm{MWh}(1.769 \mathrm{MW})$ and it takes $30.53 \mathrm{~min}$ to supply the power to the load, while the BESS capacity with a robust controller is equal to 0.612 MWh (1.835 MW) and it takes $29.42 \mathrm{~min}$. In Scenario II, the BESS capacity with a fuzzy logic controller and the power discharge duration time are equal to $0.548 \mathrm{MWh}(1.646 \mathrm{MW})$ and $33.20 \mathrm{~min}$, respectively. The BESS capacity with robust controller and the power discharge duration time are equal to $0.587 \mathrm{MWh}(1.683 \mathrm{MW})$ and $32.09 \mathrm{~min}$, respectively. Overall results shown that the BESS with fuzzy logic controller is more effective to improve the frequency/voltage stability [27]. When the microgrid is disconnected from the main grid, the BESS can supply the power to the load for approximately $30 \mathrm{~min}$. If the microgrid is reconnected to the main grid, the BESS will be charged and the SOC is kept 80 . In the worst-case scenarios, if the microgrid cannot connect to the main grid and the BESS is fully discharged, the standby generator will supply the power to the local load. 
The sizing of the BESS (MW)

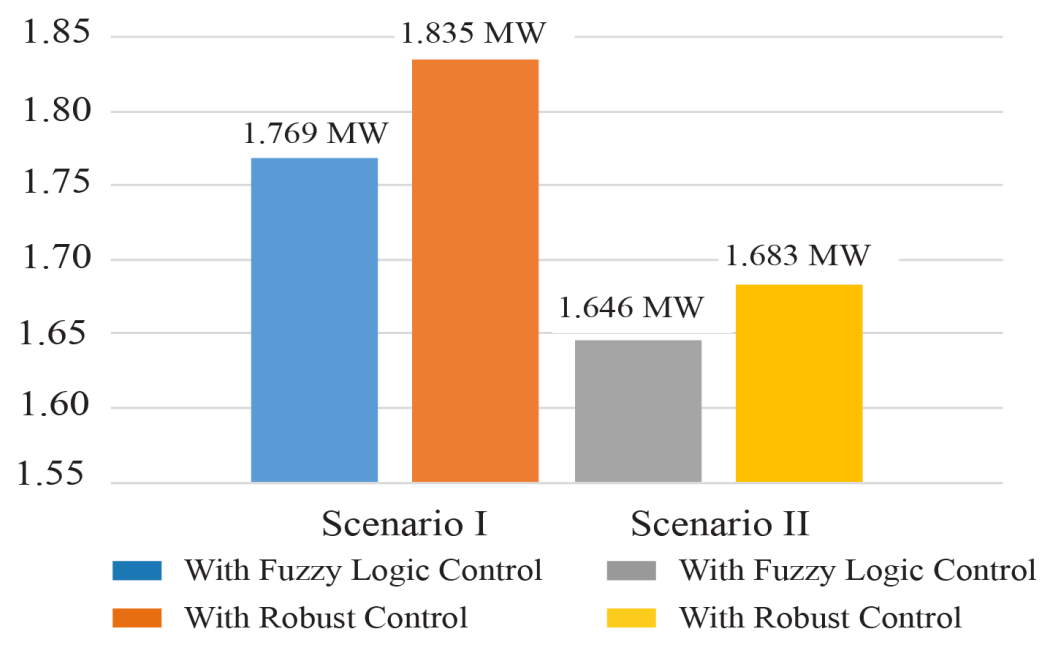

Figure 14. Comparison results of the BESS sizing.

\section{Conclusions}

This study addresses the enhanced performance of an islanded Mae Sariang microgrid utilizing a battery energy storage system (BESS) with a fuzzy logic controller. The proposed fuzzy logic control approach has an important feature that allows the BESS to rapidly respond to the output power uncertainties from RESs. To prove the performance of the proposed method, the design has been implemented on a Mae Sariang microgrid system. The verification has been performed using the DIgSILENT PowerFactory software. The performance of the proposed fuzzy logic control is compared with a well-known robust control to show the superiority of the proposed fuzzy logic control. The simulation results demonstrated that the proposed BESS fuzzy logic and robust controllers have allowed that the BESS can control the active and reactive power transfer in the microgrid during contingencies, reducing the frequency/voltage fluctuation.

However, the proposed fuzzy logic controller has been significantly examined and it provides a rapid recovery of the frequency and voltage. Moreover, the complications of the designed method have been better than the robust controller. Additionally, another highlight is the reduced energy density of the deployed BESS with the proposed fuzzy logic controller (1.769 MW for Scenario I and 1.646 MW for Scenario II), which is smaller than the BESS with robust controller.

Author Contributions: N.T. proposed the BESS fuzzy logic control and wrote the paper. T.K., W.K., Y.M. and K.H. provided theoretical knowledge in the microgrid and control domain and reviewed the study.

Acknowledgments: This work was supported by the Doctoral Student Research Fund, Department of Electrical Engineering, Faculty of Engineering, Kasetsart University in association with the 2017 MOU agreement between Kasetsart University and Kyushu Institute of Technology, Japan.The authors would like to thank the Provincial Electricity Authority of Thailand for data support.

Conflicts of Interest: The authors declare no conflict of interest.

\section{Appendix A}

Parameters of the studied system: The machine data, line data, transformer data, PV and controller data, and BESS and controller data are given in Tables A1-A6, respectively. The external grid data, exciter data, and governor data are given below. All components are built-in models in DIgSILENT PowerFactory.

External grid data: Short Circuit Power $S_{k}^{\prime \prime}=130 M V A, R / X$ ratio $=0.0392$.

Exciter data of hydro generator and diesel generator: avr_ESAC4A type, $T_{r}=0.01, T_{b}=$ $0.05, T_{c}=0.1, T_{a}=0.01, K_{a}=50, K_{c}=0.1, V_{\text {rmin }}=-20, V_{\text {rmax }}=20, V_{\text {imin }}=-2, V_{\text {imax }}=2$. 
Governor data of hydro generator: gov_TGOV1 type, $T_{1}=0.1, T_{2}=0.03, T_{3}=0.2, A_{t}=$ $1, D_{t}=0.02, R=0.2, V_{\min }=0, V_{\max }=1$.

Governor data of diesel generator: DEGOV1 type, $T_{1}=0.2, T_{2}=0.1, T_{3}=0.5, T_{4}=1, T_{5}=$ $0.1, T_{6}=0.2, T D=0.01, K=15$, Droop $=0.05$ p.u., $T_{\min }=0$ p.u., $T_{\max }=1.1$ p.u.

Table A1. Machine Date.

\begin{tabular}{cccccccccc}
\hline Generator & $\begin{array}{c}x_{l} \\
\text { (p.u.) }\end{array}$ & $\begin{array}{c}x_{2} \\
\text { (p.u.) }\end{array}$ & $\begin{array}{c}x_{0} \\
\text { (p.u.) }\end{array}$ & $\begin{array}{c}x_{d} \\
\text { (p.u.) }\end{array}$ & $\begin{array}{c}x_{d}^{\prime} \\
\text { (p.u.) }\end{array}$ & $\begin{array}{c}x_{d}^{\prime \prime} \\
\text { (p.u.) }\end{array}$ & $\begin{array}{c}x_{q} \\
\text { (p.u.) }\end{array}$ & $\begin{array}{c}x_{q}^{\prime} \\
\text { (p.u.) }\end{array}$ & $\begin{array}{c}x_{q}^{\prime \prime} \\
\text { (p.u.) }\end{array}$ \\
\hline Hydro Generator & 0.1 & 0.2 & 0.1 & 2.0 & 0.3 & 0.2 & 2.0 & 0.55 & 0.2 \\
Diesel Generator & 0.1 & 0.2 & 0.1 & 2.0 & 0.3 & 0.16 & 2.0 & 0.3 & 0.2 \\
\hline
\end{tabular}

Table A2. Machine Date.

\begin{tabular}{cccccccc}
\hline Generator & $\begin{array}{c}T_{d \mathbf{d}}^{\prime} \\
\text { (p.u.) }\end{array}$ & $\begin{array}{c}T_{\boldsymbol{d 0}}^{\prime \prime} \\
\text { (p.u.) }\end{array}$ & $\begin{array}{c}\boldsymbol{T}_{\boldsymbol{q} \mathbf{0}}^{\prime} \\
\text { (p.u.) }\end{array}$ & $\begin{array}{c}\boldsymbol{T}_{\boldsymbol{q} \mathbf{0}}^{\prime \prime} \\
\text { (p.u.) }\end{array}$ & $\begin{array}{c}\boldsymbol{H} \\
\text { (s) }\end{array}$ & MVA & $\mathbf{k V}$ \\
\hline Hydro Generator & 6.67 & 0.08 & 0.4 & 0.05 & 6 & 1.5 & 3.3 \\
Diesel Generator & 6.67 & 0.09 & 6.67 & 0.08 & 4 & 7.5 & 0.38 \\
\hline
\end{tabular}

Table A3. Line Date.

\begin{tabular}{|c|c|c|c|c|c|c|c|}
\hline \multicolumn{2}{|c|}{ Bus No. } & \multirow{2}{*}{$\begin{array}{c}R 1 \\
(\mathrm{ohm} / \mathrm{km})\end{array}$} & \multirow{2}{*}{$\begin{array}{c}X 1 \\
(\mathrm{ohm} / \mathrm{km})\end{array}$} & \multirow{2}{*}{$\begin{array}{c}R 0 \\
(\mathrm{ohm} / \mathrm{km})\end{array}$} & \multirow{2}{*}{$\begin{array}{c}X 0 \\
(\mathrm{ohm} / \mathbf{k m})\end{array}$} & \multirow{2}{*}{$\begin{array}{l}\text { Length } \\
(\mathrm{km})\end{array}$} & \multirow{2}{*}{$\begin{array}{c}\text { Nominal Voltage } \\
(\mathbf{k V})\end{array}$} \\
\hline From & To & & & & & & \\
\hline 6 & 3 & 0.0018 & 0.0360 & 0.0036 & 0.0594 & 1.2 & 22 \\
\hline 6 & 7 & 0.0066 & 0.1320 & 0.0132 & 0.2178 & 6.6 & 22 \\
\hline 6 & 9 & 0.0010 & 0.0200 & 0.0020 & 0.0330 & 1.0 & 22 \\
\hline 6 & 10 & 0.0010 & 0.0200 & 0.0020 & 0.0330 & 1.0 & 22 \\
\hline 7 & 8 & 0.0010 & 0.0200 & 0.0020 & 0.0330 & 1.0 & 22 \\
\hline 11 & 6 & 0.0550 & 1.1000 & 0.1100 & 1.8150 & 105 & 22 \\
\hline
\end{tabular}

Table A4. Transformer Date.

\begin{tabular}{|c|c|c|c|c|c|c|c|c|c|}
\hline \multicolumn{2}{|c|}{ Bus No. } & \multirow{2}{*}{$\begin{array}{c}R 1 \\
\text { (p.u.) }\end{array}$} & \multirow{2}{*}{$\begin{array}{c}X 1 \\
\text { (p.u.) }\end{array}$} & \multirow{2}{*}{$\begin{array}{c}u_{k} \\
\text { (p.u.) }\end{array}$} & \multirow{2}{*}{$\begin{array}{c}u_{k 0} \\
\text { (p.u.) }\end{array}$} & \multirow{2}{*}{$\begin{array}{l}\text { Vector } \\
\text { Group }\end{array}$} & \multirow[t]{2}{*}{ Tap } & \multirow{2}{*}{$\begin{array}{l}\mathrm{HV} \\
(\mathrm{kV})\end{array}$} & \multirow{2}{*}{$\begin{array}{c}\mathrm{LV} \\
(\mathrm{kV})\end{array}$} \\
\hline From & To & & & & & & & & \\
\hline 6 & 1 & 0.5 & 0.5 & 6.30 & 3.0 & YNd11 & 1.0 & 22 & 0.415 \\
\hline 6 & 5 & 0.5 & 0.5 & 3.00 & 3.0 & YNd11 & 1.0 & 22 & 0.415 \\
\hline 8 & 4 & 0.5 & 0.5 & 6.09 & 3.0 & YNd11 & 1.0 & 22 & 0.415 \\
\hline 3 & 2 & 0.5 & 0.5 & 6.48 & 3.0 & YNd11 & 1.0 & 22 & 0.415 \\
\hline
\end{tabular}

Table A5. PV and Controller Data.

\begin{tabular}{cccc}
\hline PQ Control Description & Parameters & Units & Values \\
\hline Minimum cut frequency & $f \min$ & $(\mathrm{Hz})$ & 47 \\
Frequency to start limitation & $f r$ & $(\mathrm{~Hz})$ & 51 \\
Frequency to be at 0 & $f m a x$ & $(\mathrm{~Hz})$ & 52.5 \\
\hline PV Array Description & Parameters & Units & Values \\
\hline Open-circuit voltage of module & $U l 0$ & $(\mathrm{~V})$ & 43.8 \\
MPP voltage of module & $U m p p 0$ & $(\mathrm{~V})$ & 35 \\
MPP current of module & $I m p p 0$ & $(\mathrm{~A})$ & 4.58 \\
Short-circuit current of module & $I k 0$ & $(\mathrm{~A})$ & 5 \\
Serial module number & - & - & 20 \\
Parallel module number & - & - & 140 \\
Time constant of module & $\mathrm{Tr}$ & $(\mathrm{s})$ & 0 \\
\hline
\end{tabular}


Table A6. BESS and Controller Data.

\begin{tabular}{cccc}
\hline PQ Control Description & Parameters & Units & Values \\
\hline Proporional gain for id_PI-controller & $K p$ & (p.u.) & 1 \\
Proporional gain for iq_PI-controller & $K q$ & (p.u.) & 1 \\
Integrator time constant id_PI-controller & u_min & (p.u.) & 0.2 \\
Integrator time constant iq_PI-controller & u_max & (p.u.) & 0.002 \\
Minimum discharging current & id_min & (p.u.) & -5 \\
Maximum discharging current & id_max & (p.u.) & 1 \\
Minimum reactive current & iq_min & (p.u.) & -5 \\
Maximum reactive current & iq_max & (p.u.) & 1 \\
\hline Simple Battery Description & Parameters & Units & Values \\
\hline State of charge at initialisation & SOC0 & (int) & 0.8 \\
Capacity per cell & CellCapacity & (Ah) & 80 \\
Voltage of empty cell & Impp0 & (V) & 12 \\
Voltage of full cell & Ik0 & (V) & 13.85 \\
Amount of parallel cells & CellsParallel & (int) & 60 \\
Amount of parallel row & CellsInRow & (int) & 65 \\
Internal resistance per cell & RiCell & (ohm) & 0.001 \\
\hline Frequency Control Description & Parameters & Units & Values \\
\hline Deadband for frequency control & SOC0 & (db) & 0.004 \\
Full active power within 1Hz/ 2Hz & droop & (p.u./p.u.) & 0.0002 \\
\hline & & & \\
\hline & & &
\end{tabular}

\section{Appendix B}

The state-space matrices $(A, B, C$, and $D)$ for the $\mathbf{Q}$ and $\mathbf{P}$ controller loops:

$$
\begin{gathered}
A_{q}=\left[\begin{array}{ccccc}
-169.6 & -10.62 & -0.5971 & -0.0374 \\
1 & 0 & 0 & 0 \\
0 & 1 & 0 & 0 \\
0 & 0 & 1 & 0
\end{array}\right], B_{q}=\left[\begin{array}{l}
1 \\
0 \\
0 \\
0
\end{array}\right]^{T}, C_{q}=\left[\begin{array}{c}
-0.116 \\
7.4935 \\
-0.059 \\
0.067
\end{array}\right]^{T}, D_{q}=\left[\begin{array}{l}
0 \\
\end{array}\right] \\
A_{p}=\left[\begin{array}{cccccc}
-4.638 & -2.554 & -3.621 & -0.468 & -0.024 & 0 \\
1 & 0 & 0 & 0 & 0 & 0 \\
0 & 1 & 0 & 0 & 0 & 0 \\
0 & 0 & 1 & 0 & 0 & 0
\end{array}\right], B_{p}=\left[\begin{array}{l}
1 \\
0 \\
0 \\
0 \\
0 \\
0
\end{array}\right]^{T}, C_{p}=\left[\begin{array}{c}
0 \\
0 \\
0 \\
0 \\
8.965 \\
1.004
\end{array}\right]^{T}, D_{p}=[0] .
\end{gathered}
$$

The weighting transfer functions for the $Q$ and $P$ controller loops:

$\omega_{1 p}=\omega_{1 q}=\frac{50 s+5}{s+3}, \omega_{2 p}=\omega_{2 q}=1$.

\section{References}

1. Lu, Z.X.; Wang, C.X.; Min, Y. Overview on microgrid research. Autom. Electr. Power Syst. 2000, 31, 100-107.

2. Lidula, N.W.A.; Rajapakse, A.D. Microgrids research: A review of experimental microgrids and test systems. Renew. Sustain. Energy Rev. 2011, 15, 186-202. [CrossRef]

3. Basaka, P.; Chowdhury, S.; Halder, S.; Chowdhury, S.P. A literature review on integration of distributed energy resources in the perspective of control, protection and stability of microgrid. Renew. Sustain. Energy Rev. 2012, 16, 5545-5556. [CrossRef] 
4. Karimi, Y.; Oraee, H.; Mohammad, S.; Guerrero, M. Decentralized Method for Load Sharing and Power Management in a PV/Battery Hybrid Source Islanded Microgrid. IEEE Trans. Power Electron. 2017, 32, 3525-3535. [CrossRef]

5. Inthamoussou, A.; Queralt, J.; Bianchi, D. Control of a super capacitor energy storage system for microgrid applications. IEEE Trans. Energy Convers. 2013, 28, 690-697. [CrossRef]

6. Ding, Z.; Yang, C.; Zhang, Z.; Wang, C.; Xie, S. A novel soft-switching multiport bidirectional DC-DC converter for hybrid energy storage system. IEEE Trans. Power Electron. 2014, 29, 1595-1609. [CrossRef]

7. Zamora, R.; Srivastava, K. Controls for microgrids with storage: Review, challenges, and research needs. Renew. Sustain. Energy Rev. 2010, 14, 2009-2018. [CrossRef]

8. Martin, I. Analyzing the Need for a Balancing System in Supercapacitor Energy Storage Systems. IEEE Trans. Power Electron. 2018, 33, 2162-2171.

9. Hisham, M.; Dennis, M.; Jin, J. Strategies for Independent Deployment and Autonomous Control of PV and Battery Units in Islanded Microgrids. IEEE J. Emerg. Sel. Top. Power Electron. 2015, 3, 742-755.

10. Etxeberria, A.; Vechiu, I.; Camblong, H.; Vinassab, J.M. Comparison of Sliding Mode and PI Control of a Hybrid Energy Storage System in a Microgrid Application. Energy Procedia 2011, 12, 966-974. [CrossRef]

11. Sharav-Schapiro, N.; Palmor, Z.J.; Steinberg, A. Robust output feedback stabilizing control for discrete uncertain SISO systems. IEEE Trans. Autom. Control 1996, 41, 1377-1381. [CrossRef]

12. Lee, H.; Tomizuka, M. Robust adaptive control using a universal approximator for SISO nonlinear systems. IEEE Trans. Fuzzy Syst. 2000, 8, 96-106.

13. Xiangbin, Y.; Leung, S.; Wu, B.; Rui, Y.; Xu, D.; Kuang, Q. Power Control for Space-Time-Coded MIMO Systems with Imperfect Feedback over Joint Transmit-Receive-Correlated Channel. IEEE Trans. Veh. Technol. Soc. 2015, 64, 2489-2501.

14. Weitzel, T.; Glock, C.H. Energy management for stationary electric energy storage systems: A systematic literature review. Eur. J. Oper. Res. 2018, 264, 582-606. [CrossRef]

15. Holger, C.H.; Michael, S.; Daniel, K.; Andreas, J. Lithium-Ion Battery Storage for the Grid-A Review of Stationary Battery Storage System Design Tailored for Applications in Modern Power Grids. Energies 2017, 10, 2107. [CrossRef]

16. Tummasit, N.; Premrudeepreechacharn, S.; Tantichayakorn, N. Adaptive overcurrent protection considering critical clearing time for a microgrid system. In Proceedings of the 2015 IEEE Innovative Smart Grid Technologies-Asia (ISGT ASIA), Bangkok, Thailand, 3-6 November 2015.

17. Nisar, A.; Shaji, M. Comprehensive Control for Microgrid Autonomous Operation with Demand Response. IEEE Trans. Smart Grid 2017, 8, 2081-2089. [CrossRef]

18. Tsikalakis, A.G.; Hatziargyriou, N.D. Centralized control for optimizing microgrids operation. IEEE Trans. Energy Convers. 2008, 23, 241-248. [CrossRef]

19. Katiraei, F.; Iravani, M.R.; Lehn, P.W. Micro-Grid Autonomous Operation During and Subsequent to Islanding Process. IEEE Trans. Power Deliv. 2015, 20, 248-257. [CrossRef]

20. CIGRE Thailand. Available online: http://www.cigre-thailand.org/tncf/events/seminar2014/mae-hongson.pdf (accessed on 17 May 2018).

21. Ithiam, W.; Asadamonkol, S.; Sumranwanich, T. Smart grid national pilot project in Mae Hong Son Province, Thailand. J. Energy Environ. 2015, 26, 23-34.

22. United Nations Development Programme (UNDP) Project Document. Promoting Renewable Energy in Mae Hong Son Province. GEF project ID: 3359, UNDP PIMS ID: 39082013.

23. United Nations Development Programme (UNDP) in Thailand. Available online: http://www.th.undp.org/ content/thailand/en/home/operations/projects/environment-and-energy/REinMHS.html (accessed on 17 May 2018).

24. Wang, J.; Chialin, N.; Feng, X.; Monti, A. Design of a Generalized Control Algorithm for Parallel Inverters for Smooth Microgrid Transition Operation. IEEE Trans. Ind. Electron. 2015, 62, 4900-4914. [CrossRef]

25. Tephiruk, N.; Hongesombut, K. Enhancement of Stabilizing Performance of a Microgrid Using Energy Storage System with Under Frequency Relay. Int. Rev. Electr. Eng. 2016, 11, 635-643. [CrossRef] 
26. Alajmi, N.; Ahmed, H.; Finney, J.; Williams, W. Fuzzy-Logic-Control Approach of a Modified Hill-Climbing Method for Maximum Power Point in Microgrid Standalone Photovoltaic System. IEEE Trans. Power Electron. 2011, 26, 1022-1030. [CrossRef]

27. Spahic, E.; Sakkanna, C.P.S.; Pieschel, M.; Alvarez, R. Multilevel STATCOM with power intensive energy storage for dynamic grid stability-frequency and voltage support. In Proceedings of the 2015 IEEE Electrical Power and Energy Conference (EPEC), London, ON, Canada, 26-28 October 2015; pp. 73-80.

(c) 2018 by the authors. Licensee MDPI, Basel, Switzerland. This article is an open access article distributed under the terms and conditions of the Creative Commons Attribution (CC BY) license (http:/ / creativecommons.org/licenses/by/4.0/). 